\title{
RANCANG BANGUN WEB SERVER UNTUK MESIN PENGERING RUMPUT LAUT BERBASIS INTERNET OF THINGS
}

\author{
Tomy Dwi Cahyono ${ }^{1}$, Eri Sasmita Susanto ${ }^{2}$, Rhomadon $^{3}$,Indra Darmawan ${ }^{4}$
}

1 Fakultas Teknologi Pertanian Universitas Teknologi Sumbawa

2,3,4 Fakultas Teknik Universitas Teknologi Sumbawa

*Corresponding Author email: tomy.dwi.cahyono@uts.ac.id, eri.sasmita.susanto@uts.ac.id,

indra.darmawan@uts.ac.id

\begin{tabular}{ll}
\hline & Abstrak \\
\cline { 2 - 2 } Diterima : & Penelitian ini bertujuan untuk merancang dan membangun web server untuk mesin \\
Bulan September & pengering rumput laut berbasis internet of things (IoT) berfungsi mengeringkan rumput \\
2020 & $\begin{array}{l}\text { laut dari basah hingga kering kawat dengan suhu panas yang termonitori. Suhu panas } \\
\text { merupakan faktor utama yang menentukan durasi pengeringan. Penelitian ini } \\
\text { menggunakan metode pengembangan perangkat lunak waterfall dan dibangun dengan }\end{array}$ \\
Diterbitkan : & menggunakan PHP 7 dan javascript. Metode pengumpulan data menggunakan teknik \\
Bulan Oktober & observasi, wawancara dan studi literature dan menggunakan metode pengujian black box \\
2020 & yaitu pengujian yang dilakukan dengan menguji perangkat lunak dari segi fungsionalitas. \\
& Hasil dari penelitian yaitu web dapat diakses melalui website yang dilengkapi dengan \\
Keyword : & fitur management user sehingga dapat memberikan kontribusi untuk karyawan samawa \\
Web Server, & inspirasi. \\
Internet of Things, & \\
Monitoring &
\end{tabular}

\section{PENDAHULUAN}

Internet of Things (IoT) adalah salah satu tren baru dalam dunia teknologi yang kemungkinan besar akan menjadi salah satu hal besar di masa depan. IoT merupakan suatu konsep yang bertujuan untuk memperluas manfaat dari konektivitas internet yang tersambung secara terus-menerus (Kurniawan, 2016).

IoT dapat menggabungkan antara benda-benda fisik dan virtual melalui eksploitasi data capture dan kemampuan berkomunikasi. Sederhananya dengan IoT benda-benda fisik di dunia nyata dapat berkomunikasi satu dengan yang lain dengan menggunakan bantuan jaringan dan internet. Selain untuk berkomunikasi antar obyek dunia nyata, IoT juga bisa digunakan untuk hal lain seperti pengambilan data dari suatu tempat dengan menggunakan sensor dan juga akses jarak jauh untuk mengendalikan benda lain di suatu tempat. Kemampuan akses dari IoT bisa saja tidak terbatas berkat perangkat IoT yang selalu tersambung ke internet, sehingga dapat diakses dan digunakan kapan saja dan juga di mana saja.

CV. Samawa Inspirasi merupakan salah satu start up yang terdapat di kabupaten Sumbawa. Industri ini bergerak pada komoditi rumput laut yang mana hal tersebut akan menjadi produk derivatif. Berdasarkan hasil peninjauan, perusahaan tersebut sedang memperbesar skala produksinya dengan menggunakan mesin pengering rumput laut berkapasitas $100 \mathrm{~kg}$.
Mesin tersebut berfungsi untuk mengeringkan rumput laut berskala besar yang berjenis rotary. Pada dasarnya, mesin ini memanfaatkan energi panas untuk mengeringkan rumput laut dan dinamo listrik untuk menggerakkan rotary di dalam inkubator sehingga dengan mekanisme kerja seperti itu, mesin tersebut membutuhkan lama waktu kurang lebih 4 jam untuk mengeringkan rumput laut dari basah hingga kering kawat dengan suhu panas . Suhu panas merupakan faktor utama yang menentukan durasi pengeringan. Di samping itu, permasalahan yang krusial dari mesin pengering rumput laut ini adalah kesulitan untuk mendapatkan akurasi lama waktu pengeringan yang optimal, hal yang menyebabanya adalah karena tidak tersedianya indikator suhu pada inkubator mesin. Maka dari itu, IoT sangat dibutuhkan untuk memonitori suhu dan kelembaban.

\section{LANDASAN TEORI}

Perkembangan teknologi yang sangat pesat berdampak pada bertambah banyaknya protokol jaringan khususnya protokol jaringan untuk komunikasi client dengan suatu perangkat. Munculnya berbagai jenis protokol tersebut menimbulkan satu masalah yaitu membuat pengembangan sistem menjadi rumit. Untuk mengatasi masalah tersebut dibutuhkan protokol jaringan yang sederhana dan sering digunakan kebanyakan orang. Selain membutuhkan teknologi jaringan, agar perangkat seperti aktuator atau sensor dapat bekerja maka dibutuhkan sebuah teknologi 
komputer berupa mikrokontroler yang berfungsi sebagai pengolah data baik itu data yang akan dikirimkan ke perangkat atau data yang diterima dari perangkat (Awal, 2019).

Modul ESP8266 merupakan modul WIFI, yang banyak digunakan untuk aplikasi Internet Of Thing (IoT) seperti mengendalikan aktuator dan membaca sensor. Sistem pengendalian tersebut dapat berbentuk protokol MQTT ataupun web server yang tertanam dalam memory IC ESP8266 tersebut. Penerapan pengendalian tersebut dapat dilakukan pada alat-alat rumah tangga. Alat rumah tangga ini dapat mati dan hidup dengan kontrol dari internet dan dapat dikendalikan secara otomatis dengan web. Web ini menampilkan waktu kapan menyala dan kapan waktu ketika mati. Proses ini akan menghemat penggunaan listrik di rumah, karena pemakaian peralatan rumah tangga sesuai dengan kebutuhan pemilik rumah (Priya, 2017).

\section{Rancang Bangun}

Rancang bangun merupakan bagian-bagian dari sistem lama yang kemudian dirancang kembali untuk memperbaharui sistem yang sudah ada dan kemudian menciptakan sistem baru atau memperbaharui sistem sebelumnya agar menjadi lebih baik (Ardhianto, 2015).

Rancang bangun adalah tahap awal dari membuat gambaran dan bentuk sketsa yang belum pernah dibuat sama sekali lalu dikelola menjadi gambaran atau sketsa yang memiliki fungsi yang digunakan (Sandro, 2013).

\section{Web Server}

Web Server adalah suatu cara mengakses informasi dari sebuah internet, web juga bisa dikatakan sebagai media yang digunakan sebagai media untuk mengakses informasi melalui internet (Muhammad, 2019)

\section{Internet of Things}

Internet of Things (IoT) adalah sebuah konsep dimana suatu objek mati memiliki kemampuan untuk menerima dan mengirimkan sebuah data melalui koneksi jaringan. Bisa juga disebut interaksi manusia dengan sebuah perangkat, di mana perangkat tersebut digunakan untuk mengontrol sebuah lingkungan atau memonitori kondisi sebuah lingkungan. Selain membutuhkan perangkat seperti sensor dan aktuator, untuk mengimplementasikan konsep IoT dibutuhkan peran serta teknologi lain, seperti teknologi komputer dan teknologi jaringan untuk mencapai tujuan yang di inginkan (Noor 2018)

\section{Monitoring}

kegiatan pemantauan yang di maksudkan untuk membuat sebuah pengukuran atas pergerakan ke arah yang dituju disebut monitoring (Hendini, 2016).

\section{Waterfall}

Waterfall adalah metode klasik yang sistematis dalam membangun sebuah perangkat lunak. Metode ini tergolong ke dalam model generik pada rekayasa perangkat lunak. Pendekatan yang dilakukan sistematis dan berurutan menjadi alasan mengapa metode ini disebut waterfall (Roger, 2012).

Metode waterfall memiliki fase sebagai berikut:

a. Communication (Project Initiation \& Requirements Gathering)

Memahami permasalahan dan kebutuhan customer guna mendefinisikan tujuan yang ingin dicapai adalah hal yang wajib dilakukan sebelum mulai mengerjakan hal yang bersifat teknis. Dalam tahapan ini dilakukan inisisalisasi proyek seperti menganalisis permasalahan yang sedang dialami oleh customer dan mengumpulkan datadata yang diperlukan, serta mendefinisikan software yang akan dibangun.

b. Planning (Estimating, Scheduling, Tracking) Tahap planing atau perencanaan akan menjelaskan estimasi dan tugas-tugas teknis yang akan dilakukan, risiko, sumber daya yang dibutuhkan, produk yang ingin dihasilkan, penjadwalan kerja dan tracking proses pengerjaan sistem.

c. Modeling (Analysis \& Design)

Pada tahapan ini dilakukan perancangan serta permodelan arsitektur dari sistem software yang akan dibangun. Kegiatan ini berfokus pada perancangan struktur data, arsitektur software, interface dan algoritma program. Tujuan dari kegiatan tersebut adalah untuk memahami gambaran dari apa yang akan dikerjakan.

d. Konstruksi (Code \& Test)

Tahapan ini dilakukan proses penerjemahan hasil analisis dan desain ke dalam bentuk kode program. Kegiatan ini lebih dikenal dengan istilah pengkodean atau programing. Setelah proses pengkodean selesai, sistem atau software tersebut harus melewati tahapan pengujian untuk memastikan apakah hasil implementasi telah sesuai dengan rancangan.

e. Deployment (Delivery, Support, Feedback)

Deployment merupakan tahapan implementasi software ke customer, pemeliharaan software secara berkala, evaluasi software dan pengembangan software berdasarkan permintaan customer supaya sistem dapat tetap berjalan dan berkembang.

\section{Unified Modelling Language (UML)}

UML merupakan sebuah bahasa permodelan yang telah menjadi standar dalam industri software untuk visualisasi, merancang, dan mendokumentasikan sistem perangkat lunak. Desain yang dihasilkan berupa diagram-diagram yang diterjemahkan menjadi kode program. Terdapat 13 jenis diagram resmi yang digunakan dalam perancangan berorientasi objek berbasis UML (Hendini, 2016).

a. Use Case Diagram diagram merupakan permodelan untuk behavior sistem informasi 
yang akan dibuat. Use case digunakan untuk mengetahui apa saja yang ada di dalam sistem informasi dan siapa saja yang berhak menggunakan fungsi-fungsi tersebut.

b. Activity Diagram menggambarkan workflow (aliran kerja) atau aktivitas dari sebuah sistem atau proses bisnis.

c. Sequence Diagram menggambarkan kelakuan objek pada use case dengan mendeskripsikan waktu hidup objek dan pesan yang dikirimkan dan diterima antar objek.

d. Class Diagram Merupakan hubungan antar kelas dan penjelasan detail tiap-tiap kelas di dalam model desain dari suatu sistem, juga memperlihatkan aturan-aturan dan tanggung jawab entitas yang menentukan perilaku sistem. Class diagram juga menunjukkan atribut atribut dan operasi-operasi dari sebuah kelas dan constraint yang berhubungan dengan objek yang dikoneksikan.

\section{Black Box}

Black box yaitu pengujian yang dilakukan dengan menguji perangkat lunak dari segi fungsionalitas perangkat lunak yang diuji sesuai dengan use case pada tahap permodelan. Setiap bagian diuji sesuai dengan skenario pada tahap permodelan dan proses pengujian menggunakan emulator (Mustaqbal, 2015).

\section{MATODE PENELITIAN}

Penelitian ini menggunakan metode penelitian kualitatif yang bersifat deskriptif. Penelitian yang menitikberatkan pada pengukuran dan analisis hubungan sebab-akibat antara bermacam-macam variabel, bukan prosesnya, penyelidikan dipandang berada dalam kerangka bebas nilai. Metode perancangan dalam penelitian ini menggunakan pendekatan Waterfall. Adapun alur dalam penelitian ini disajikan pada Gambar 1.

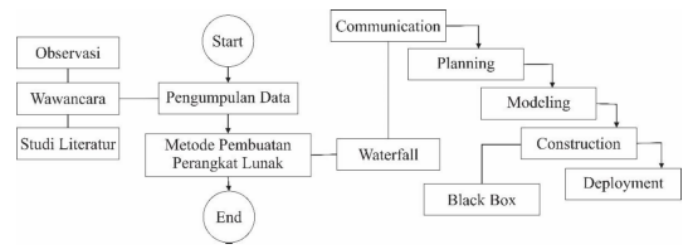

Gambar 1. Diagram Alir Penerlitian

\section{HASIL DAN PEMBAHASAN}

\section{Rancangan Sistem}

Rancangan sistem web server dalam penelitian ini dibagi menjadi 4 bagian, yang mana setiap bagian diwakilkan oleh digram waterfall . Adapun diagram tersebut disajikan sebagai berikut:
1. Use Case Diagram

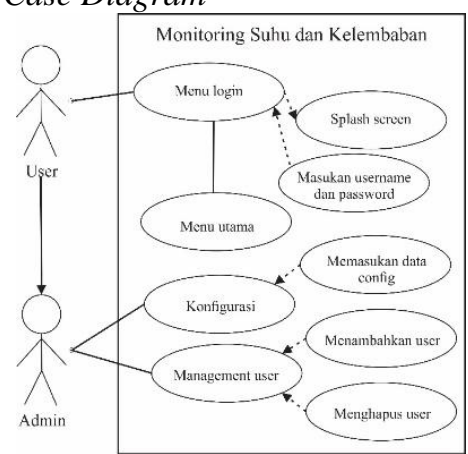

2. Activity Diagram

a. Konfigurasi

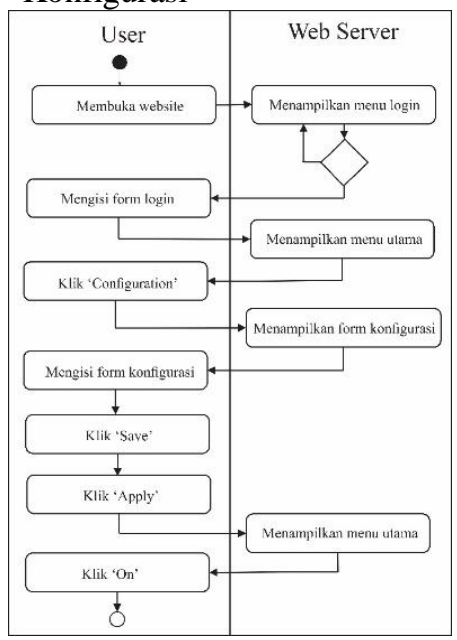

b. Tambah user

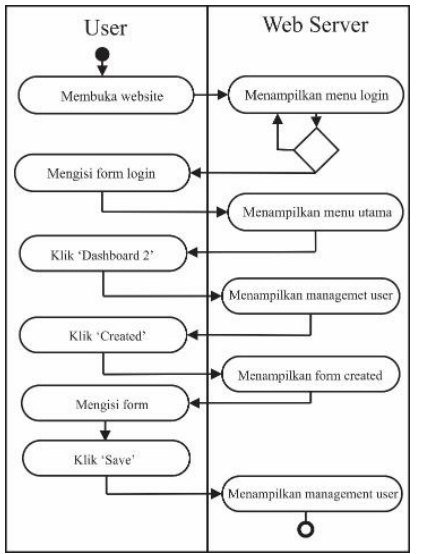

c. Activity Diagram Keseluruhan

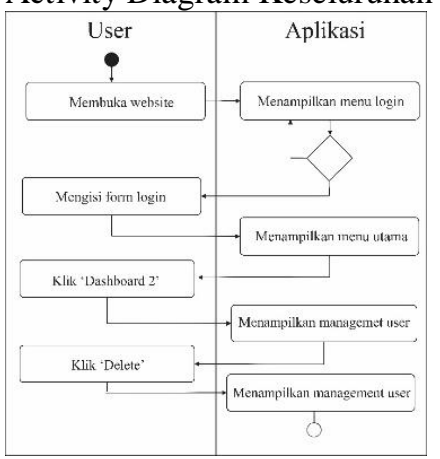


3. Sequence Diagram

a. Konfigurasi

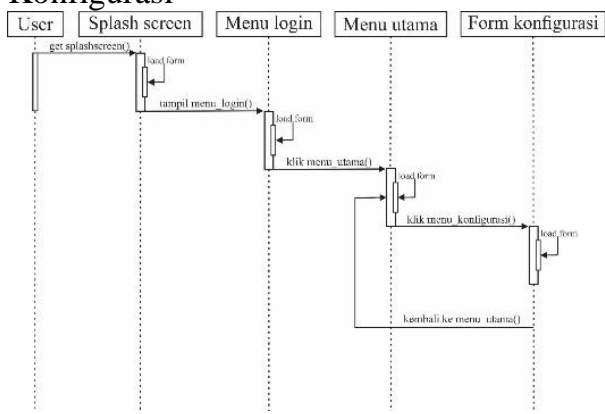

b. Tambah User

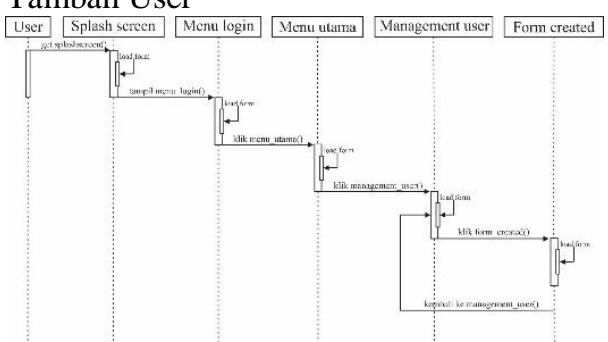

c. Hapus User

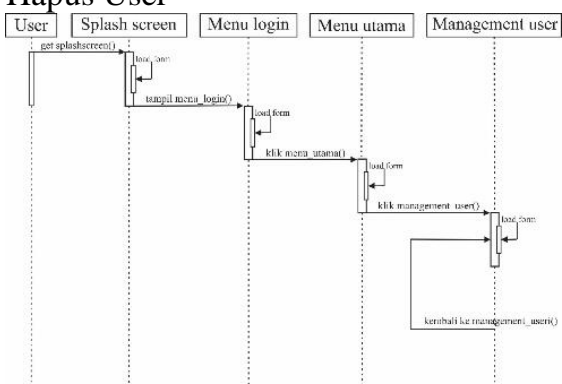

4. Class Diagram

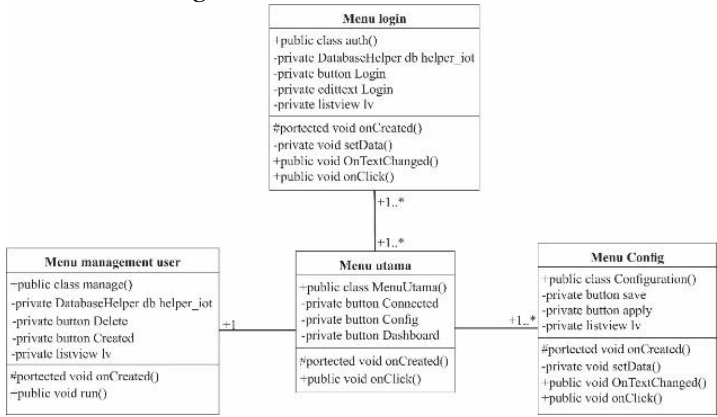

\section{Pengujian Perangkat}

Proses pengujian dalam penelitian ini dilakuukan dengan black box testing, maka diperoleh hasi pengujian sebagai berikut:

1. Pengujian Splash Screen

Hasil pengujian fungsionalitas splash screen menunjukkan bahwa ketika user memulai membuka web, reaksi perangkat lunak yang ditunjukkan yaitu menampilkan splash screen. Berdasarkan hasil tersebut dapat dikatakan bahwa hasil pengujian fungsionalitas splash screen telah selesai.

2. Pengujian menu login

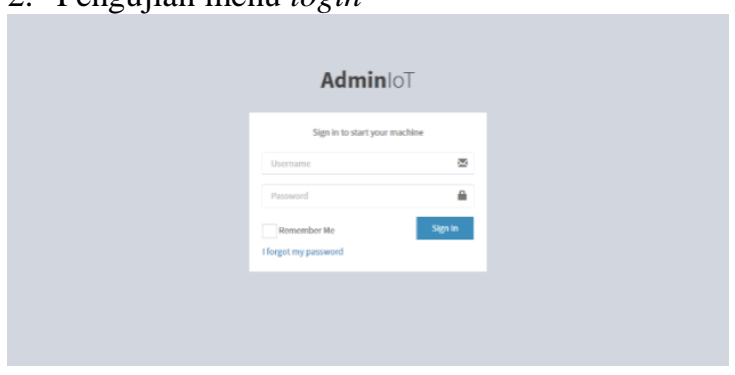

Hasil pengujian fungsionalitas menu login menunjukkan bahwa ketika user memulai membuka web, reaksi sistem yang ditunjukkan setelah splash screen yaitu menampilkan menu login yang terdiri dari yang terdiri dua textbox dan satu button untuk login. Berdasarkan hasil tersebut dapat dikatakan bahwa hasil pengujian fungsionalitas menu login adalah sesuai.

3. Pengujian menu utama

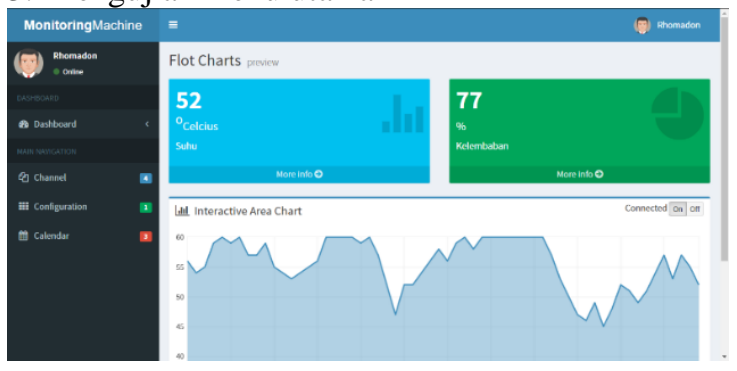

Hasil pengujian fungsionalitas menu utama menunjukkan bahwa ketika user berhasil masuk. Reaksi sistem yang ditunjukkan setelah menu login yaitu menampilkan menu utama yang terdiri dari informasi suhu dan kelembaban dengan dua button. Berdasarkan hasil tersebut dapat dikatakan bahwa hasil pengujian fungsionalitas menu utama adalah sesuai.

\section{Pengujian form konfigurasi}

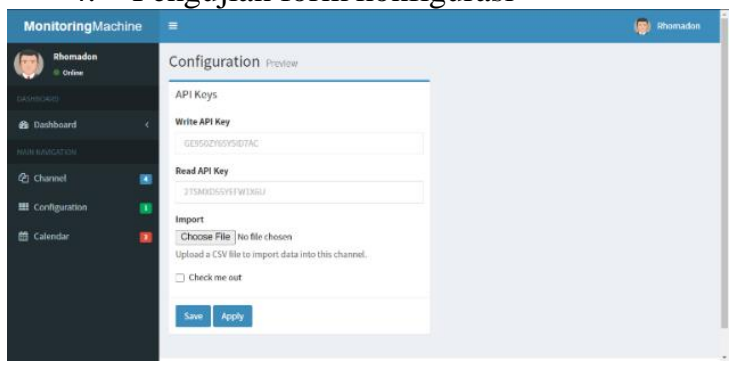

Hasil pengujian fungsionalitas menu form konfigurasi menunjukkan bahwa ketika user telah masuk pada menu utama dan menekan tombol configuration. Beralih ke menu konfigurasi menampilkan menu konfigurasi setelah menekan tombol configuration. Terdapat listview yang memiliki satu cekbox dan dua button. Berdasarkan 
hasil tersebut dapat dikatakan bahwa hasil pengujian fungsionalitas menu form konfigurasi adalah sesuai.

5. Pengujian menu managemet user

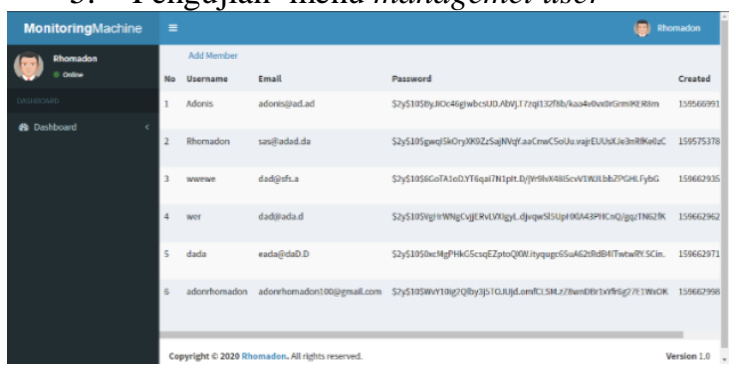

Hasil pengujian fungsionalitas menu managemet user menunjukkan bahwa ketika user telah masuk pada menu utama dan menekan tombol dashboard. Beralih ke menu managemet user menampilkan menu managemet user setelah menekan tombol dashboard. Menampilkan menu management user setelah menekan tombol dashboard. Terdapat listview berupa rows dari data username yang dapat menambahkan dan menghapus row. Berdasarkan hasil tersebut dapat dikatakan bahwa hasil pengujian fungsionalitas menu form konfigurasi adalah sesuai.

\section{PENUTUP}

\section{Kesimpulan}

Kesimpulan yang dapat diambil dari skripsi ini yaitu web Server untuk mesin pengering rumput laut berbasis IoT sudah berhasil dibangun dengan menggunakan PHP dan telah di upload ke website. Setelah dilakukan uji coba dengan smartphone dan pc telah berhasil menampilkan suhu dan kelembaban serta menambahkan dan menghapus karyawan.

\section{REFERENSI}

A. Hendini. 2016. "Pemodelan UML Sistem Informasi Monitoring Penjualan dan Stok Barang (Studi Kasus: Distro Zhezha Pontianak)," vol. IV, no. 2, pp. 201-205.

Awal, Hasri. 2019. "Perancangan Prototype Smart Home Dengan Konsep Internet Of Things (IoT) Berbasis Web Server”. Majalah Ilmiah UPI YPTK vol no 26, no 2 hal 64-79.
E. Ardhianto. 2015. "Rancang Bangun E-Office Administrasi Agenda Kegiatan Promosi Unisbank Semarang”. J. Teknol. Inf. Din., vol. 20 , no. 1 , pp. $17-24$.

Kurniawan. 2016. "Purwa Rupa IoT (Internet of Things) Kendali Lampu Gedung (Studi Kasus pada Gedung Perpustakaan Universitas Lampung)". Skripsi, Teknik Elektro, Teknik, Universitas Lampung, Bandar Lampung.

M. S. Mustaqbal, R. F. Firdaus, H. Rahmadi, 2015 "Pengujian Aplikasi Menggunakan Black Box Testing Boundary Value Analysis (Studi Kasus : Aplikasi Prediksi Kelulusan SNMPTN)," vol. I, no. 3, pp. 31-36.

Mulyono, Yumari. 2017. "Strategi Monitoring dan Evaluasi Pelaksanaan Anggaran". Yogyakarta: Deepublish.

Nirwan A Noor, dkk. 2018. "Implemntasi Web ServerThingspek Pada Alat Ukur Parameter Portable Solar Panel," Prosiding Seminar Hasil Penelitian (SNP2M).

O. Fajarianto. 2016. "Prototype Pelayanan Akademik Terhadap Komplain Mahasiswa Berbasis Mobile," J. Lentera Ict, vol. 3, no. 1, pp. 54-60.

P. Rizki. Priya. 2017. “Aplikasi Web Server ESP8266 Untuk Pengendali Peralatan Listrik". Invotek Vol. 17, No. 2.

R. Muhammad, M. Gian, A Molavi. 2019. "Perbandingan Performansi Single Web Server Dan Multi Web Server Dengan Metode Paired Sample T Test". Jurnal SISFOKOM, vol 08, no 02.

S. P. Roger. 2012. "Rekayasa Perangkat Lunak (Pendekataan Praktisi)”. Edisi 7. Yogyakarta.

Sembiring Sandro. 2013. "Perancangan Aplikasi Steganografi Untuk Menyisipkan Pesan Teks Pada Gambar Dengan Metode End of File". Pelita Inform. Budi Darma, vol. IV, no. Agustus, pp. 45-51. 